\title{
Educational Protocol for Improving Mothers Practices on the Types of Fever in Zagazig City
}

Reda El-Sayed El-Badawy Ezzat ${ }^{{ }^{*}}$, Fatma Khalil Abd-Elhameed ${ }^{2}$

${ }^{1}$ Lecturer of community health Nursing, Faculty of Nursing, Zagazig University, Egypt

${ }^{2}$ Assistant professor of community health Nursing, Military Medical Academy, Egypt

DOI: $10.36348 /$ sjnhc.2020.v03i01.001

| Received: 17.12.2019 | Accepted: 24.12.2019 | Published: 11.01.2020

*Corresponding author: Reda El-Sayed El-Badawy Ezzat

\section{Abstract}

Background: Fever is a common medical problem among children that always prompts mothers to seek medical care. Aim: To evaluate the effect of educational protocol for improving mothers' practices on the types of fever in Zagazig City. Design: A quasi-experimental research design [pretest -posttest] was used. Setting: At Chiba MCH center, in Zagzig City. Sample: A purposive sample consisted of 96 mothers were chosen according to inclusion criteria. Tools: Three tools were used; Interview Questionnaire sheet, the mothers' knowledge of fever, and mothers' practice in management of their febrile child. Results: Showed that about 33.33\% of the mothers aged between 35 and 40 years, about $72.91 \%$ of them were married, nearly $64.58 \%$ of them had work. Also, about $63.54 \%$ of them reported that they were from rural areas. Also, there were statistically significant totally improvements in the mothers' knowledge and practices regarding the focused problem at $(\mathrm{p}<0.001)$ in the post-protocol phase. There were highly statistically significant positive correlation between mothers' total knowledge and practices pre and post-protocol $(\mathrm{r}=0.802$, and 0.617) respectively. Conclusion: The applying of educational protocol among mothers was effective in enhancing their knowledge, and practices regarding types of fever and their management. Recommendation: Further educational protocols in the pediatric clinics or via mass media for mothers about fever should be implemented.

Keywords: Educational Protocol, Fever, and Mothers Practices.

Copyright @ 2020: This is an open-access article distributed under the terms of the Creative Commons Attribution license which permits unrestricted use, distribution, and reproduction in any medium for non-commercial use (NonCommercial, or CC-BY-NC) provided the original author and source are credited.

\section{INTRODUCTION}

Many children consistently suffer from a lot of infectious diseases; in which the main primary symptom in any these infections is fever. Actually, the majority of those mothers are not aware about the fever control measures. If the fever is not controlled, it can lead to many complications such as convulsions and irreversible brain damage [1].

Fever can be defined as "an elevation of body temperature above the normal daily variation", normal temperature is described as between 36 and $36.8{ }^{\circ} \mathrm{C}$; Fever accounts for $6 \%$ of visits to paediatricians, along with numerous visits to General Practitioners (GPs), emergency departments (EDs), primary care Pediatricians and out-of-hours care services [2].

In fact, the fever response is a hallmark of any infection or inflammatory disease and has been shaped through hundreds of millions of years of natural selection [3]. Common viral and bacterial diseases are the most likely illnesses to cause fever. These include: colds, gastroenteritis, ear infections, croup, bronchiolitis, urinary tract infections, also, some childhood immunizations can cause fever; the timing of the fever varies, depending upon which vaccination was given, furthermore, there is little or no scientific evidence to support the widespread belief that teething causes fever [4].

Out of the many reasons for high parental concern regarding fever, misconception that fever is a disease rather than a symptom has been most commonly reported. The numerous misconceptions regarding fever cause increased maternal anxiety that has existed globally since long [5].

There are many ways for measuring the body temperature such as in the axilla, rectum, mouth, skin, or ears, but there are substantial differences among those measurement sites. For example, the rectal way is considered to be the most accurate way to estimate core body temperature [6]. 
In this time mothers tend to do aggressive handling towards an increase in body temperature of the child; thus an antipyretic drug may be administered to reduce fever-related complications, which, if the child is given excessively and inappropriately may cause complications and hepatotoxicity. This happens because of a lack of information about the fever and its benefits as well as the inconsistent handling of fever in many hospitals [7].

Health education protocol in the form of interaction between mothers and health professionals such as community health nurse; can offer health benefits by sharing experiences and knowledge and encouraging healthy life habits, essential for the protection and promotion of child health, with contributions from professionals for mothers to serve as active participants in childcare in many cases like fever [8].

Indeed, the main objective of managing fever is to protect and comfort the child until a real diagnosis of the underlying condition is made, mothers can often manage their child's temperature at home with simple ways like regular fluids and rest (National Collaborating Centre for Women's and Children's Health (UK) [9].

Community health nurse has a main role in health education of mothers; they can give them educational advices about maintaining their children health so that they can decrease the occurrence of disorders and deaths. They also can make educational assemblies, hand -out fliers, conduct health screenings, dispense medications and administer immunizations. Additionally, the nurse should provide mothers with written and verbal information about the main causes of fever and also the risk of subsequent events; furthermore, it is essential to educate them that fever is a sign for infection and not a disease itself [10].

\section{Significance of the Study}

Although the incidence of serious infections has decreased after the introduction of conjugate vaccines, fever remains a major cause of laboratory investigation and hospital admissions. In the same line with the 2030 Agenda, the Egyptian Government has launched a working plan called Egypt's Vision 2030, also known as Sustainable Development Strategy (SDS), which covered three dimensions; and in response to those dimensions; the aim of the study was to evaluate the effect of educational protocol for improving mothers practices on the types of fever in Zagazig City.

\section{Hypothesis}

- Implementation of the educational protocol for mothers, improves their knowledge, and practices on the types of fever.
Aim:

To evaluate the effect of educational protocol for improving mothers practices on the types of fever in Zagazig City.

\section{The aim of this study was full filled through the following objectives}

- Assessed knowledge and practice of mothers about types of fever.

- Designed an educational protocol to mothers to enhance their knowledge, and practices according to their needs.

- Evaluated the effect of the protocol for the mothers.

\section{SUBJECTS AND METHOD \\ Design:} this research.

Quasi experimental design was used to make

\section{Setting:}

At Chiba MCH center, at Zagzig City.

There are four Maternal and Child Health Centers in Zagazig City; and then the researcher randomly selected one of them (Chiba MCH center) for the study.

\section{Sample:}

A total sample of 96 mothers was recruited to participate in this study.

The sample size was determined according to the following equation:

$$
N=(Z \alpha)^{2} \times p q / d^{2} \text {, Sahai and Khurshid, } 1996
$$

[11].

The estimated sample sizes will be:

$\mathbf{n}=$ sample size.

$\mathbf{Z} \boldsymbol{\alpha}=$ the value of standard normal distribution for type I error probability for the sided test and equals 1.96.

$\mathbf{p}=26 \%$.

$\mathbf{q}=1-\mathrm{p}$

$\mathbf{d}^{2}=$ the accuracy of estimate $=(0.05)^{2}$

This subject was chosen according to the following criteria:

\section{Inclusion Criteria}

1. Having at least a child at any age less than or equal 12 years.

2. Aged between 20 and 40 years old.

3. Regular attendance to the $\mathrm{MCH}$ center.

4. Verbal accepting taking part in the protocol.

5. Not sharing in other similar protocols. 
Tools for Data Collection

Interview Questionnaire sheet: It was developed by the investigator, it was consisted of two parts:-

A) First part: This part was about demographic characteristics of mothers; included closed questions such as age, residence, level of education, and occupation.

B) Second part: The characteristics of the children; that consist of some questions like: gender, age, education.

Tool (II): The mothers' knowledge of fever: This tool was developed by AlAteeq, et al.,[12]; an Arabic tool contained 6 items; such as: definition of normal temperature and high temperature, fever health effects, and source of information about fever.

\section{Scoring System}

The scores of the items was summed -up and the total was divided by the number of items giving a means of score for the part. Theses scores were converted into percent score, means and standard deviations was computed, Correct/complete answer $=2$ degree, Correct/incomplete answer $=1$ degree, and Incorrect answer $=$ zero.

Total scores were accounted according to the following:

- Good is $>75 \%$ of total knowledge score.

- Fair is from 60 to $75 \%$ of total knowledge score.

- Poor less than $60 \%$ of total score.

Tool (III): mothers' practice in management of their febrile child: This tool was developed by AlAteeq $e t$ al., [12] an Arabic tool including 9 items such as: how they measure the temperature, what fever treatment given without prescription, when they decide to visit the health providers, and what difficulty they encounter when giving medication.

\section{Scoring System}

Responses were measured in all questions on a score as following: 1 score for steps that was incorrectly, and 2 scores for steps that was correct

Total score was accounted according to the following:

- Satisfactory is $\geq 60 \%$ of total score.

- Unsatisfactory is $<60 \%$ of total attitude score.

\section{Content Validity}

The validity of tools had done through five expertise professors of Community Health Nursing Specialties, from different Faculties of Nursing. The tools were modified based on their guidance and views.

\section{Reliability}

All tools for data collection were tested for its reliability using test retest reliability and all tools were proved to be strongly reliable. This was done using the assessment of their internal consistency. The reliability proved to be high based on the values of Cronbach alpha coefficients. The tools are proved to be strongly reliable $(\mathrm{r}=0.8222)$.

\section{Field work:}

1- The researcher conducted an intensive review of the past and current related literature covering various aspects of the "types of fever and their management" and associated knowledge, and practices. This was done using available textbooks and articles in scientific periodicals and journals. Based on this review, the tools were prepared in their preliminary forms, and reviewed by a panel of nursing specialists for face and content validation. The review also helped in developing a basic framework of the educational protocol.

2- An official permission was obtained using proper channels of communication. This was done through letters addressed from the Faculty of Nursing, Zagazig University; elucidating the objectives and procedures of the research and asking for cooperation to the Directors of the Chiba MCH center, in Zagzig City.

3- Informed oral consent was obtained from the participants.

4- The investigator met with the subjects, introduced her-self and elucidated the purpose of the research to obtain their consent to participate in the study and gain their cooperation and confidence.

5- The participants were interviewed individually before applying the planned sessions to collect the baseline data using all study tools.

6- A pilot study was done on $10 \%$ of the sample to ensure the clarity, applicability and feasibility of the study tools, necessary modifications were done, and they were excluded after that.

7- The researcher started to fill-out the questionnaire from sample. The researcher read and explained each item to the students and recorded their responses to each item. This interview took about 15 to 20 minutes.

8- The execution of the study was through four phases, namely assessment, planning, implementation, and evaluation. This lasted for 6 months from the first of December 2018 to the end of June 2019.

9- The objective of the program was to improve knowledge, practice, of the mothers.

10- The program was implemented in the form of 10 sessions. The duration of each session ranged between thirty minutes and forty-five minutes. The sessions were implemented in small homogeneous groups in the $\mathrm{MCH}$ center; each group consisted of 5-10 mothers according to their attendance. The sessions were administered two days per week for each 
study group. They were held on Monday and Wednesday.

11- The program was implemented through various teaching methods as short lectures, group discussions, brain storming, demonstration re-demonstration, and role-play. The teaching media included power-point presentations and a handbook.

12- Every session was started by a summary about what was taken at the last session and the objectives of the new one to make sure that mothers recognize the content, taking into consideration the use of simple language to suit the level of education of mothers. Motivation and reinforcement techniques as praise and recognition were used during the session to enhance participation and learning.

13- The researcher designed an illustrative booklet in simple Arabic language to be distributed to mothers.

\section{Description of the Program}

General objective of the program:

To improve knowledge, practices of mothers regarding types of fever.

\section{Specific Objectives \\ By the end of this program}

- The mothers will be able to discuss simple information about types of fever.

- The mothers will be able to summarize the main causes and complications with their children regarding to the focused problem.

- The mothers will be able to deal correctly with their children case.

The protocol sessions consisted of two main components

- The first component was for giving a theoretical background of types of fever such as definition, patterns, causes, effects and types, complications; (this included 5 sessions)

- The second main component was for giving practical sessions about practices of mothers regarding febrile child (this included 5 sessions).

\section{Evaluation Phase}

- Immediately after the end of the sessions. Evaluation was done to assess the impact of the protocol.

\section{Ethical Considerations}

- Anonymity, confidentiality and privacy of the mothers were assured.

- Voluntary participation and right to refuse to participate in the study was emphasized to the subjects.

- Verbal consent was taken at the beginning of the study from mothers.

\section{STATISTICAL ANALYSIS}

Data entry and statistical analysis were done using SPSS 20.0 statistical software package. Qualitative variables were compared using qui square test (X2) as the test of significance. A significant level value was considered when $\mathrm{p}$-value $\leq 0.05$ and a highly significant level value was considered when $p$-value $\leq 0.001$, while $\mathrm{p}$-value $>0.05$ indicates non-significant results.

\section{RESULTS}

Table-1 showed the distribution of demographic characteristics of mothers' children in the study sample. The table showed that the mean age of the children was $8.4158 \pm 2.38267$, with about $58.33 \%$ of them aged between days to less than one year; also $76.04 \%$ of them were males.

Table-2 showed the demographic characteristics of studied mothers; the table showed that $33.33 \%$ of the mothers aged between 35 and 40 years, about $72.91 \%$ of them were married, nearly $64.58 \%$ of them had work. Also, about $63.54 \%$ of them reported that they were from rural areas.

Figure-1 showed the distribution of studied mothers according to their educational level. The figure revealed that about $62.50 \%$ of mothers had secondary level of education, while just $20.83 \%$ of them were university.

Figure-2 showed total knowledge score of the study sample. The figure revealed statistically significant totally improvements in the mothers' knowledge regarding fever at $(\mathrm{p}<0.001)$ in the postprotocol phase. Overall, about $5.20 \%$ of the mothers had good knowledge before the sessions and that percent had been increased to $77.08 \%$ after the implementation of the educational protocol.

Figure-3 showed Total scores of mothers' practice in management of their febrile child at the study. The figure revealed statistically significant totally improvements in the mothers' practices regarding management of their febrile children at $(\mathrm{p}<0.001)$ in the post-protocol phase. Overall, the total satisfactory practices of the mothers increased from $20.83 \%$ at the pre phase to $87.50 \%$ after the implementation of the protocol.

Table-3 displayed Relation between the mothers' total knowledge and their practices pre and post protocol. It demonstrated that there were highly statistically significant differences between mothers' total knowledge and practices pre and post-protocol.

Table-4 displayed correlation between the mothers' total knowledge and their practices pre and post protocol. It demonstrated that there were highly statistically significant positive correlation among 
mothers' total knowledge and practices pre and postprotocol ( $\mathrm{r}=0.802$, and 0.617 ) respectively.

Table-1: Distribution of demographic characteristics of mothers' children in study subjects $(n=96)$

\begin{tabular}{|l|l|l|}
\hline Demographic items & Frequency & $\%$ \\
\hline Age & 56 & 58.33 \\
\hline days $<1$ year & 23 & 23.95 \\
\hline $1-<5$ & 17 & 17.70 \\
\hline $5-12$ & $\mathbf{8 . 4 1 5 8} \pm 2.38267$ \\
\hline Mean \pm SD & 23 & 23.95 \\
\hline Gender & 73 & 76.04 \\
\hline Female & \multicolumn{2}{|l|}{} \\
\hline Male & 18.75 \\
\hline Level of education & 18 & 15.62 \\
\hline Nursery & 15 & 65.62 \\
\hline school & 63 &
\end{tabular}

Table-2: Demographic characteristics of studied mothers $(\mathbf{n}=96)$

\begin{tabular}{|c|l|l|}
\hline Items & No & $\%$ \\
\hline Age of mothers (in years) & & \\
\hline$\bullet \quad 20:<25$ & 13 & 13.54 \\
\hline$\bullet \quad 25:<30$ & 21 & 21.87 \\
\hline$\quad 30:<35$ & 30 & 31.25 \\
\hline$\bullet \quad 35: 40$ & 32 & 33.33 \\
\hline Marital status & & \\
\hline$\bullet \quad$ Married & 70 & 72.91 \\
\hline$\bullet \quad$ Divorce & 18 & 18.75 \\
\hline$\bullet \quad$ Widow & 8 & 8.33 \\
\hline Occupation & & \\
\hline$\bullet \quad$ Working & 62 & 64.58 \\
\hline$\bullet \quad$ House wife & 34 & 35.41 \\
\hline Residence & 61 & 63.54 \\
\hline Rural & 35 & 36.45 \\
\hline Urban & \\
\hline
\end{tabular}

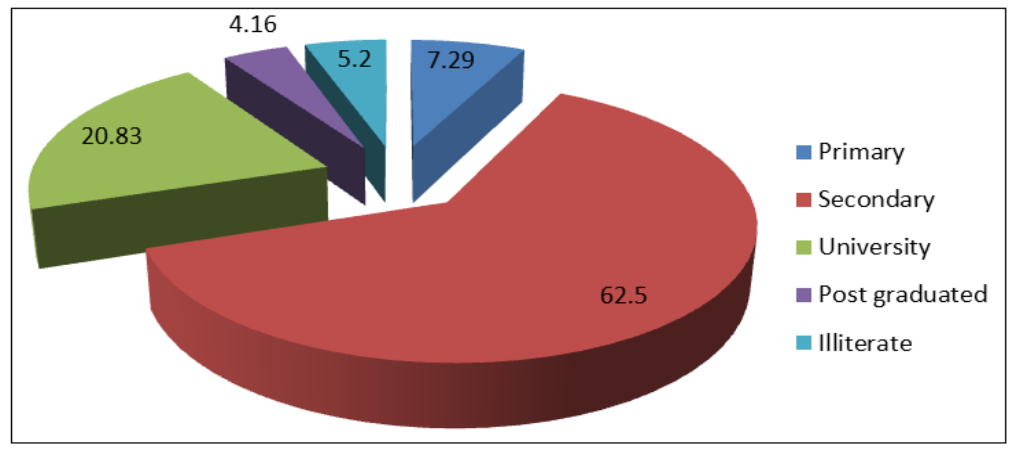

Fig-1: Distribution of studied mothers according to their educational level (n=96)

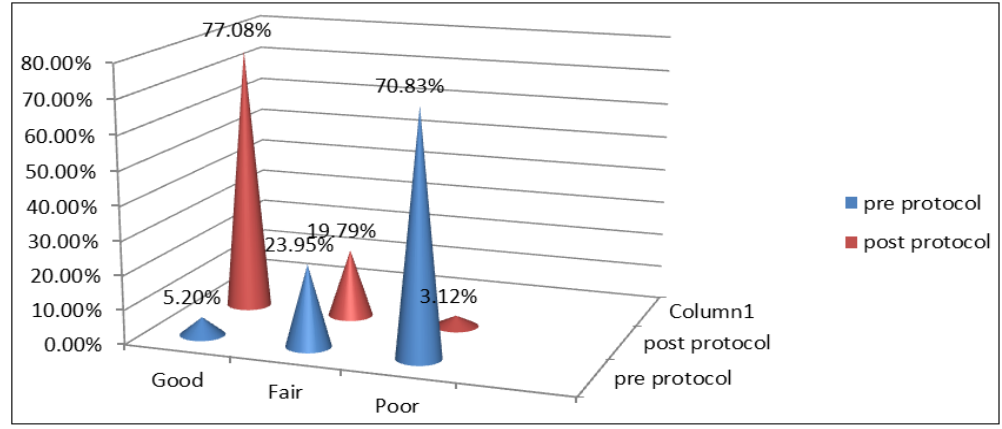

Fig-2: Total knowledge score of the study sample (n=96)

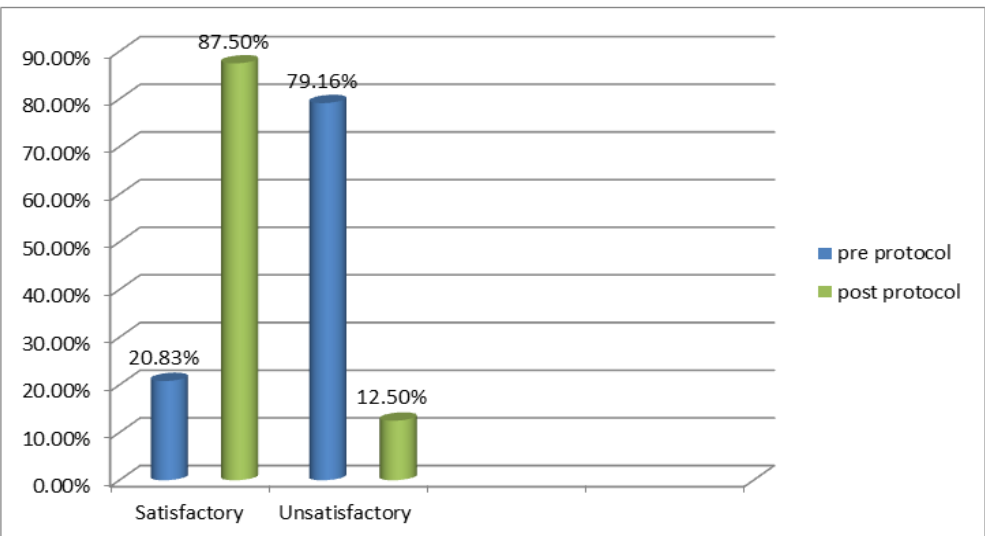


Fig-3: Total scores of mothers' practice in management of their febrile child at the study, $(n=96)$

Table-3: Relation between the mothers' total knowledge and their practices pre and post protocol $(n=96)$

\begin{tabular}{|l|l|l|l|l|l|l|}
\hline \multirow{2}{*}{ Items } & Pre protocol & \multicolumn{2}{|l|}{ Post protocol } & \multirow{2}{*}{$\mathbf{X}^{2}$} & \multirow{2}{*}{ P-value } \\
\cline { 2 - 5 } & No & $\%$ & No & $\%$ & & \\
\hline Total knowledge & 5 & 11.45 & 74 & 77.08 & \multirow{2}{*}{127.527} & $0.000^{*} * *$ \\
\hline Good & 23 & 23.95 & 19 & 19.79 & & \\
\hline Fair & 68 & 70.83 & 3 & 3.12 & & \\
\hline Poor & 20 & 20.83 & 84 & 87.50 & \multirow{2}{*}{102.561} & $0.000^{* * *}$ \\
\hline Total practice \\
\hline Satisfactory & 76 & 79.16 & 12 & 12.50 & & \\
\hline Unsatisfactory & 76 &
\end{tabular}

Table-4: Correlation between the mothers' total knowledge and their practices pre and post protocol $(n=96)$

\begin{tabular}{|l|l|l|l|l|}
\hline \multirow{2}{*}{ Total knowledge } & \multicolumn{3}{|l|}{ Total knowledge } \\
\cline { 2 - 5 } Total practice & Pre protocol & \multicolumn{2}{l|}{ Post protocol } \\
\hline \multirow{3}{*}{ Total practices } & $\mathbf{r}$ & P-value & $\mathbf{r}$ & P-value \\
\cline { 2 - 5 } & $\mathbf{0 . 8 0 2}$ & $0.000^{* * *}$ & $\mathbf{0 . 6 1 7}$ & $0.000^{* * *}$ \\
\hline
\end{tabular}

\section{DISCUSSION}

Fever is a combined symptom among children; that often related to a rapidly self-limiting disease and its main effect is discomfort. Misconceptions by mothers about rare serious causes such as severe bacterial infections beginning with isolated fever and specific complications of fever (e.g., convulsions) have resulted in a "phobia" about that sign, and also led to many wrong thing done by mothers in response to that fever [13].

Regarding to the demographic characteristics of studied mothers; the present results showed that $33.33 \%$ of the mothers aged between 35 and 40 years.

This finding disagreed with Silva et al., [8], in Brazilian city, as they mentioned that most of mothers in their study were in the age between 16 to 25 years.

Also, the current results showed that more than two thirds of mothers had work. This finding disagreed with the findings mentioned by Ravanipour et al., [14] at their research about mothers' perceptions of fever in children; as they revealed that the majority of their subjects were housewives.

As related to the distribution of studied mothers according to their educational level; the current results revealed that about two thirds of mothers had secondary level of education.

This finding disagreed with the results done by Ravanipour et al., [14] as they revealed that the majority of their subjects had an educational level above the bachelor's degree.

Regarding the residence of the studied subjects, the recent results showed that nearly two thirds of them reported that they were from rural areas.

This finding might be attributed to the setting of data collection in Zagazig City at El-Sharkia governorate which characterized by its agricultural nature and most of its cities are rural areas.

This current finding agreed with Do et al., [15], in their research that done in Mali, Nigeria, and Madagascar; they reported that two-thirds of the sample reported lived in rural areas.

Regarding the demographic characteristics of mothers' children in the study subjects; the current study showed that nearly two thirds of the children aged between days to less than one year.

The finding was disagreed with Herman and Nurshal [16], in their study about in Pariaman's General Hospital, West Sumatera, Indonesia, that the age of the majority of children who were hospitalized with a fever the most was the age of toddlers (1-3 years).

Additionally, the current study revealed that most of the children were males. This finding agreed with Teferi et al., [13], in their results in Butajira, South-Central Ethiopia; as they reported that about most of their studied mothers were boys.

Regarding total knowledge score of the study sample before the protocol; the current study revealed that only about $5.20 \%$ of the mothers had good knowledge before the implementation of the educational sessions.

This poor level of knowledge could be explained by the low level of education of the studied mothers as the current results illustrated that about two thirds of mothers had secondary level of education. Additionally, it could be cleared the reduction and lack of educational awareness campaigns in Egypt, generally.

Those present results agreed with Bont et al., [17], in their research to study knowledge, attitudes, and practice in childhood fever in parents within the general 
population of the Netherlands; as they mentioned that the majority of their participants had poor knowledge about fever.

The finding was disagreed with AlAteeq et al., [12], in their study in Riyadh, Saudi Arabia, among mothers; as they mentioned that about more than half of their subjects had enough information about fever. Also, the results in present study disagreed with Herman and Nurshal [16], in their study in Pariaman's General Hospital, West Sumatera, Indonesia, as they mentioned that the majority of respondents had adequate knowledge about the handling of the fever in children.

Additionally, this finding disagreed with Tagbo et al., [18], in Nireria, as they revealed in their results that about ninety one percent of mothers in their research were concerned about fever and its harmful effects.

Regarding total knowledge score of the study sample after the implementation of the educational protocol; the present findings revealed statistically significant totally improvements in the mothers' knowledge regarding fever at $(\mathrm{p}<0.001)$ in the postprotocol phase. Overall, about $5.20 \%$ of the mothers had good knowledge before the protocol sessions and this percent had increased to $77.08 \%$ after the implementation of the educational protocol.

These good amendments in the level of the participant's knowledge could elucidate the favorable impact of the sessions of the educational protocol and how the subjects were interested and cooperative within the intervention.

Similarly [19], mentioned in their Egyptian study at Mansoura University Children's Hospital that the implementation of educational sessions and also mothers support group were influenced positively in enhancing mothers' knowledge. Similarly to these present findings [1], concluded in their study in India that educational program about treatment of children suffering from pyrexia was effective in increasing the level of knowledge of mothers.

Additionally [16], found in their study in Pariaman's General Hospital, West Sumatera, Indonesia; that there were significant differences on knowledge score (p value: 0.009 ), of parents among the case group and the control group.

Regarding total scores of mothers' practice in management of their febrile child at the study before the sessions; the present study declared that the total satisfactory practices of the mothers was only among about $20.83 \%$ of mothers at the pre phase of the implementation of the educational protocol.
This highly unsatisfactory practices of mothers in the present study before the implementation of the protocol sessions could be due to their poor level of knowledge and also their low level of education as mentioned before in the current results. Furthermore, it could reflex the lack of awareness in Egypt and the need for more health educations for them. This explanation could be supported by Badawy et al., [20] as they reviewed in their study in Kuwait that the level of education had a positive impact on the practices of fever $[\chi 2(\mathrm{df}=8)=70.68, \mathrm{p}<0.001]$.

These results agreed with Villarejo-Rodríguez, and Rodríguez-Martín [21], in their comparison study between the health professional and non-health professional parents about management of fever in Spain, as they mentioned that most of the parents had unsatisfactory practices.

The finding was disagreed with AlAteeq et al., [12], in their study in Riyadh, Saudi Arabia, among mothers; as they mentioned that most of their participants knew the basic practices about management of fever for their children.

As related to total scores of mothers' practice in management of their febrile child at the study after the implementation of the educational protocol; fortunately, the sessions of the educational protocol of the study positively changed the students' practices; as most of the study sample changed to satisfactory level of their practices after the protocol with significant totally improvements in the mothers' practices regarding management of their febrile children at $(p<0.001)$ in the post-protocol phase. This could profess the success of these sessions and declare the positive effect of the practical sessions of the protocol on the participants. Also, this positive change reflexed the formidable role of education in improving the practices regarding management of fever.

Similarly, Arias et al., [22], illustrated in their study about an educational interventions on fever management in children, in Australia, that most interventions reported a positive impact in fever management skills.

Also, this finding was similar to Bertille et al., [23] in their results in France, they reported that their recommendations about managing fever in children to parents were effective in changing the parents' practices with their children.

Regarding the relation between the mothers' total knowledge and their practices pre and postprotocol; the present study demonstrated that there were highly statistically significant differences among mothers' total knowledge and practices pre and postprotocol. 
This finding disagreed with Elbilgahy and Abd El Aziz [19], in their Egyptian research as they reported that there were a relation between their studied mothers' total knowledge scores and their total practices and attitudes scores but the relation was not statistically significant.

Regarding the correlation among the mothers' total knowledge and their practices pre and postprotocol; the present results were demonstrated that there were highly statistically significant positive correlation between mothers' total knowledge and practices pre and post-protocol $(\mathrm{r}=0.802$, and 0.617 ) respectively; that means when the knowledge level increased, the level of practices would also increase.

This finding was similar to a study done in Kuwait by Badawy et al., [20] as they reported in this study that there positive correlation between parent's knowledge of their children's fever and their patterns to manage the fever homely. Additionally, the same correlation was reported in the results of Tafti et al., [24], in their research in Tehran, Iran.

\section{CONCLUSION}

The study findings led to the conclusion that the mothers had poor level of knowledge, and also unsatisfactory practices regarding fever before the protocol. Fortunately, the implementation of sessions was effective and enhanced their practice, and knowledge. Moreover, there were highly statistically significant differences among mothers' total knowledge and practices pre and post-protocol and also positive correlation among mothers' total knowledge and practices.

\section{RECOMMENDATION}

Based on the study findings, the following recommendations can be deduced:

1. Further educational protocols in the pediatric clinics or via mass media for mothers about fever should be implemented.

2. Attitudes and perceptions regarding fever and its management for mothers or also of both parents could be assessed.

3. Training on first aid for management of fever at home should be given to mothers in different sittings.

4. Educational pamphlets about fever and its management should be given to all mothers or caregivers in different settings such as, out patients' clinics, hospitals and schools.

\section{ACKNOWLEDGEMENTS}

The researchers want to thank all the mothers who were in the research sessions and staff at Chiba $\mathrm{MCH}$ center, in Zagzig City, for their help and cooperation during the study period.

\section{REFERENCES}

1. Naregal, P., Mohite, V., Hiremath, P., Chendake, M., Karale, R., Pawar, S., \& Ujwala R. (2017). Effectiveness of Health Education on Knowledge of Mothers of Under Five Children Regarding Management of Children Suffering from Pyrexia. Asian Journal of Pharmaceutical Research and Health Care. 9(1): 22-27.

2. Kelly, M., Sahm, L., Shiely, F., O’Sullivan, R., McGillicuddy, A., \& McCarthy, S. (2016). Parental knowledge, attitudes and beliefs regarding fever in children: an interview study. BMC Public Health. 16(1):540-547.

3. Evans, S., Repasky, E., \& Fisher, D. (2015). Fever and the thermal regulation of immunity: the immune system feels the heat. Journal of Nat Rev Immunol. 15(6):335-349.

4. Ward, A. (2019). Patient education: Fever in children (Beyond the Basics). Online article. Retrieved

from: https://www.uptodate.com/contents/fever-inchildren-beyond-the-basics. Accessed on: 29\10\2019.

5. Thota, S., Ladiwala, N., Sharma, P., \& Ganguly, E. (2018). Fever awareness, management practices and their correlates among parents of under five children in urban India. International Journal Contemp Pediatrics. 5(4):1368-1376.

6. Barbi, E., Marzuillo, P., Neri, E., Naviglio, S., \& Krauss, B. (2017). Fever in Children: Pearls and Pitfalls. J of children. 4(81):1-19.

7. Ludwig, J., \& Whinnie, H. (2019). Antipyretic drugs in patients with fever and infection: literature review. British Journal of Nursing. 28(10): 610-618.

8. Silva, F., Gondim, E., Henrique, N., Fonseca, L., \& Mello, D. (2018). Educational intervention involving young mothers: gaining knowledge on childcare. Journal of Acta Paulista de Enfermagem. 31(1):32-38.

9. National Collaborating Centre for Women's and Children's Health (UK). (2013). NICE guideline: Feverish illness in children - Assessment and initial management in children younger than 5 years, Vol. C160. London: National Institute for Health and Care Excellence.

10. Corley, A., Thornton, C., \& Glass, N. (2016). The Role of Nurses and Community Health Workers in Confronting Neglected Tropical Diseases in SubSaharan Africa: A Systematic Review. Journal of PLoS ONE. 12(4):12-23.

11. Sahai, H., \& Khurshid, A. (1996). Formulae and tables for the determination of sample sizes and power in clinical trials for testing differences in proportions for the two-sample design: a review. 15(1):1-21.

12. AlAteeq, M., AlBader, B., Al-Howti, S., Alsharyoufi, M., \& Abdullah, J. (2018). Parent's knowledge and practice in home management of 
fever in their children in Riyadh, Saudi Arabia. Journal Family Med Prim Care. 7(5):1012-1018.

13. Teferi, M., Desta, M., Yeshitela, B., Beyene, T., Espinoza, L., Im, J., Jeon, H., Kim, J., Konings, F., \& Kwon, S. (2019). Acute Febrile Illness Among Children in Butajira, South-Central Ethiopia During the Typhoid Fever Surveillance in Africa Program. Journal of Clinical Infectious Diseases. 69(6): S483-S491.

14. Ravanipour, M., Akaberian, S., \& Hatami, G. (2014). Mothers' perceptions of fever in children. Journal Educ Health Promot. 3(1):97-112.

15. Do, M., Babalola, S., Awantang, G., Toso, M., Lewicky, N., \& Tompsett, A. (2018). Associations between malaria-related ideational factors and care-seeking behavior for fever among children under five in Mali, Nigeria, and Madagascar. Journal of PLoS ONE. 13(1):e0191079.

16. Herman, H., \& Nurshal, D. (2017). The effect of health education to parent's behaviours on managing fever in children. International Journal of Research in Medical Sciences. 5(11):47014707.

17. Bont, E., Francis, N., Dinant, G., \& Cals, J. (2014). Parents' knowledge, attitudes, and practice in childhood fever: an internet-based survey. British Journal of General Practice. 64(618):e10e16.

18. Tagbo, B., Ibeneme, C., Adimora, G., \& Ilechukwu, C. (2010). Mothers' perception and management of childhood fevers at the university of Nigeria teaching hospital (Unth), Enugu. Journal College of Medicine. 15(1):44-50.

19. Elbilgahy, A., \& Abd El Aziz, R. (2018). Effect of implementing an educational module on improving mothers knowledge, home management and attitude about febrile convulsion. Journal of Nursing Education and Practice. 8(3):1-11.

20. Badawy, N., Alhajraf, A. F., \& Alsamdan, M. F. (2017). Kuwaiti parent's knowledge of their children's fever and their patterns of use of over the counter antipyretics. AMJ. 10(10):848-855.

21. Villarejo-Rodríguez, M., \& Rodríguez-Martín, O. (2019). Parental Approach to the Management of Childhood Fever: Differences between Health Professional and Non-Health Professional Parents. International Journal Environmental Research Public Health. 16(20:1-25.

22. Arias, D., Chen, T., \& Moles, R. (2019). Educational interventions on fever management in children: A scoping review. Journal of Nursing Open. 6(1):713-721.

23. Bertille, N., Fournier-Charrière, E., Pons, G., \& Martin Chalumeau, M. (2013). Managing Fever in Children: A National Survey of Parents' Knowledge and Practices in France. Journal of PLOS ONE, 8(12):e83469.

24. Tafti, B., Salmani, N., \& Afshari-azad, S. (2016). The Maternal Experiences of Child Care with Fever: a Qualitative Study. International Journal of Pediatric. 12(6): 4429-4437. 